\title{
Are you a globally competent knowledge citizen?
}

\author{
Melanie Sutton \\ Knowledge Officer \\ The IQ Business Group \\ msutton@iqgroup.net
}

\section{Introduction}

Powered by the drive towards globalization, there is an ongoing transformation in the culture, strategies, structure and process that organizations employ rendering a new type of organization, the global company (Yeniyurt, Cavusgil and Hult 2004).

If today's global economy is considered to be a knowledge economy or an information society, then the rules and practices that determined success in the industrial economy of the 20 th century need rewriting in an interconnected world where resources such as know-how are more critical than other economic resources.

Are we able to function effectively in a global society in which time and space no longer insulate the nations, people and markets of the world? As technologies of travel, communications and information have brought the entire world within our reach, our need to understand international and global phenomena has expanded (Barker 2000). As knowledge citizens operating in this global environment, we are required to have a set of global competencies that will enable us to participate in this global environment. This column discusses the requirements of a globally competent knowledge citizen.

\section{Drivers of global competencies}

There are three driving forces that are changing the rules of business, competitiveness and the competencies required of the knowledge citizens:

\subsection{Globalization}

Markets and products have become more global. Products and service offerings by companies such as Nike and Virgin are known the world over. Resourcing is becoming global with many organizations outsourcing manufacturing and software development to distant locations, including India and South Africa.

For example, there is an increasing focus on South Africa and Cape Town as a Call Centre or International Offshore Customer Management site. The common language, culture and the favourable time zone and affordability of South African resources make South Africa a natural market for international customers countries.

\subsection{Information and knowledge intensity}


Efficient production relies on information and know-how; over $70 \%$ of workers in developed economies are information workers and many factory workers use their heads more than their hands.

\subsection{Networking and connectivity}

Developments such as the Internet bring the global village closer. The result is that goods and services can be developed, bought and sold and even delivered over electronic networks. Electronic commerce offers many advantages in terms of cost savings, efficiencies and market reach over traditional methods.

\section{Knowledge economy}

The knowledge economy differs from the traditional economy in several key aspects:

- The economics is not of scarcity but of abundance. Knowledge and information can be shared and actually grow through application (Skryme 1997).

- The effect of location is diminished. Using appropriate technology and methods, virtual marketplaces and virtual organizations can be created that offer benefits of speed and agility of round-the-clock operation and of global reach (Skryme 1997).

- Laws, barriers and taxes are difficult to apply solely on a national basis.

- Knowledge-enhanced products or services can command price premiums over comparable products with low embedded knowledge, or knowledge-intensity products with low embedded knowledge or knowledge intensity.

- Pricing and value depends heavily on context. The same information or knowledge can have vastly different value to different people at different times.

- Knowledge, when locked into systems or processes, has higher inherent value than when it can walk out of the door in people's heads.

- Human capital and competencies are a key component of value in a knowledge-based company (Skryme 1997).

These characteristics, so different from those of the industrial economy, require new thinking and approaches by policy makers, organizations and especially by knowledge workers or knowledge citizens (Skryme 1997).

\section{Global competence}

National boundaries have become rather irrelevant when we consider the impact of international connectivity on financial markets, patterns of migration, climate change, spread of epidemics and threats of terrorism. Global leaderships requires global competency (Kecht 2005).

Global competence is defined as the capacity to function effectively across cultures and national borders. While there is a continuing need for specialists in international and global issues, all of us are players in an increasingly global society and we must to be able to participate in and understand our place in the world (Barker 2000).

Appreciation of difference is one goal of global competence. Open mindedness about possibilities, understanding that human choices are made on the basis of different views of the way things are, recognizing that one's own view is not universally shared, resistance to stereotyping and empathy are among the other attributes of global competence (Strommer 2005).

Global competence refers to facts and understanding of global issues and affairs, seeing 
issues positively from another perspective and displaying language, task performance and interpersonal skills.

The question is twofold, how can we effectively adapt to the realities outside and what competencies do we need in order to make globalization an engine that lifts people out of hardship and misery. How can we disseminate existing knowledge and generate new knowledge in such a way that we become aware of the new realities?

\section{Characteristics of globally competent knowledge citizens}

The characteristics of a globally competent knowledge citizen can be summarized as follows:

- An ability to access information from a wide variety of sources that span the spectrum of media as well as location;

- an ability to read the information analytically and critically, recognizing the culturally coded nature of the knowledge construction;

- a desire to familiarize him/herself with multiple perspectives on any issue, crediting them with validity, before passing judgement or making choices and then to know how to draw information synthetically from the selected sources;

- work experience in other cultures and the opportunity for interaction with representatives from other countries;

- a functional level of second language proficiency;

- well-developed communications skills and ability to successfully work in a team and approach tasks in a collaborative style. Being able to reach out to individuals in other fields when complex problems are to be solved;

- well-developed communication strategies reflect comprehension of different viewpoints and flexibility in adjusting to new situations. Our communication strategies must reflect an appreciation of diverse perspectives and respect for culturally different thinking, how to work collaboratively in interdisciplinary and international teams, how to assume responsibility for a world beyond the borders of one's own country and how to recognize the need for competent and cosmopolitan engagement with global concerns;

- an understanding that one can no longer live one's life without reference to the wider world or to the historical forces that have shaped the present and will shape the future;

- cultural empathy and a conceptual framework for understanding global issues and interdependence (Kecht 2005); and

- an appreciation for and intention to take full advantage of technology - the Internet makes possible virtual international exchanges, connecting individuals and organizations around the world (Barker 2000).

\section{Conclusion}

Globalization has indeed presented some interesting opportunities and challenges and it is clear that the competences required of global knowledge citizens are strategically important for a global success. We need to get smarter in order to survive in a world without walls (Kecht 2005). A change of lifestyle, a conscious evaluation of one's own perceptions and horizons as well as serious reflection on the way one's daily actions affect the rest of the world.

However, the writer believes that most of the global requirements are not too different from general knowledge competencies that are required by all knowledge citizens bar a more encompassing understanding and openness to global culture as well as urging one to see oneself as a large human community and gain a perspective that places one in a larger context. Global knowledge citizenship is indeed a position to strive towards. 


\section{References}

Barker, C.M. 2000. Education for international understanding and global competence. [Online.] Available WWW: http://www.carnegie.org/pdf/global.pdf (Accessed 1 September 2005).

Kecht, M.R. 2005. Are faculty ready for global competence? [Online.] Available WWW: http://www.uri.edu/iep/pdf/colloquia/2000/uri_global_competence2.pdf (Accessed 1 September 2005).

Skryme, D. 1997. The global knowledge economy and its implications for markets. [Online.] Available WWW: http://www.skyrme.com/insights/21gke.htm (Accessed 1 September 2005).

Strommer, D.W. 2005. Acquiring global competence. [Online.] Available WWW: http://www.uri.edu/iep/pdf/colloquia/2000/uri_global_competence2.pdf (Accessed 1 September 2005).

Yeniyurt, S., Cavusgil, S.T. and Hult, G.T.M. 2004. A global market advantage framework: the role of global market knowledge competencies. [Online.] Available WWW: http:// http://globaledge.msu.edu/KnowledgeRoom/FeaturedInsights/A\%20global\%20market\% 20advantage\%20framework_IBR_2005.pdf (Accessed 1 September 2005).

\section{About the author}

Melanie Sutton (BA, Postgraduate Diploma in Information Management) is a Senior Principal Consultant in the Enterprise Content Management Discipline and a member of Intellectual Property Forum at The IQ Business Group, South Africa.

\section{Disclaimer}

Articles published in SAJIM are the opinions of the authors and do not necessarily reflect the opinion of the Editor, Board, Publisher, Webmaster or the Rand Afrikaans University. The user hereby waives any claim he/she/they may have or acquire against the publisher, its suppliers, licensees and sub licensees and indemnifies all said persons from any claims, lawsuits, proceedings, costs, special, incidental, consequential or indirect damages, including damages for loss of profits, loss of business or downtime arising out of or relating to the user's use of the Website. 